\title{
An efficient NSCE algorithm for multi-objective reactive power system compensation with UPFC
}

\author{
Messaoud Belazzoug ${ }^{1}$, Abdallah Chanane ${ }^{2}$, Karim Sebaa ${ }^{3}$ \\ ${ }^{1,2}$ University of Blida 1 Saâd Dahlab, Laboratoire des Systèmes Electriques et Télécommande (LABSET), Electronics \\ Department, Faculty of Technology, Blida, Algeria \\ ${ }^{3}$ University of Medea, Laboratory of Advanced Electronic Systems (LSEA), Medea, Algeria
}

\begin{tabular}{l}
\hline Article Info \\
\hline Article history: \\
Received Sep 27, 2020 \\
Revised Mar 3, 2021 \\
Accepted Mar 13, 2021 \\
\hline
\end{tabular}

\section{Keywords:}

Electrical network

NSCE

NSGA-II

Optimization

ORPF

RM-MEDA

UPFC

\section{Corresponding Author:}

Messaoud Belazzoug

University of Blida 1 Saâd Dahlab

Laboratoire des Systèmes Electriques et Télécommande (LABSET)

Electronics Department, Faculty of Technology, Blida 09000, Algeria

Email: belazzoug.messaoud@univ-blida.dz

\begin{abstract}
This paper proposes a novel approach based on the NSCE (elitist non dominated sorting cross entropy), for the optimization of the location and the size of a flexible AC transmission system device (FACTS) namely: unified power flow controller (UPFC) to achieve the optimal reactive power flow (ORPF). In the present work, the main objective is to minimize the real power losses, the cost investment of several UPFC and the deviation voltages using intelligent algorithms. The proposed study is multiobjective, in which, the power generator buses, the control voltages, the ratio tap changer of transformers and the reactive power injections from installed UPFC are considered as control variables. The proposed NSCE algorithm is validated on IEEE 30-bus test system. A comparison with elitist non dominated sorting genetic algorithm (NSGA-II) and a regularity model-based multiobjective estimation of distribution algorithm (RMMEDA) is done and completed with hybridization of them.
\end{abstract}

This is an open access article under the CC BY-SA license.

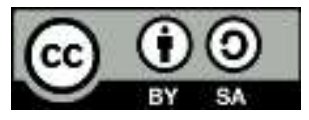

\section{NOMENCLATURE}

$\overline{\boldsymbol{V}}_{\boldsymbol{i}} \quad$ Complex voltage at the node $\mathrm{i}$ in $\mathrm{pu}$.

$\overline{\boldsymbol{V}}_{\boldsymbol{j}} \quad$ Complex voltage at the node $\mathrm{j}$ in pu.

$\bar{V}_{b} \quad$ Complex voltage of serial source in UPFC

in pu.

$\bar{V}_{e} \quad$ Complex voltage of shunt source in UPFC

$V_{e} \quad$ in pu.

$\bar{S}_{i} \quad$ Complex Apparent power injected in node

$S_{i} \quad$ i in pu.

$\bar{S}_{j} \quad$ Apparent power injected in node $\mathrm{j}$ in pu. $\quad T_{i}$

$\overline{\boldsymbol{Y}}_{\boldsymbol{e}} \quad$ Shunt complex Admitance of UPFC in pu.

$\mathbf{X}_{\mathbf{e}} \quad$ Shunt reactance of UPFC in pu.

$\overline{\boldsymbol{Y}}_{\boldsymbol{b}} \quad$ Serial complex Admitance of UPFC.

$Y_{\boldsymbol{e}} \quad$ Shunt Admitance of UPFC in pu

$Y_{\boldsymbol{b}} \quad$ Serial Admitance of UPFC in pu.

\begin{tabular}{|c|c|}
\hline$Q_{g i}^{\max }$ & $\begin{array}{l}\text { Upper bound of reactive power generation in } \\
\text { MW. }\end{array}$ \\
\hline$N_{g}$ & Number of generation nodes. \\
\hline$V_{g i}$ & Voltage at Generation node iin pu. \\
\hline$V_{g i}^{\min }$ & Lower voltage at generation node $\mathrm{i}$ in $\mathrm{pu}$. \\
\hline$V_{g i}^{\max }$ & Upper voltage at generation node $\mathrm{i}$ in pu. \\
\hline$T_{i}$ & Tap ratio transformer at line i in pu. \\
\hline$T_{i}^{\min }$ & $\begin{array}{l}\text { Lower ratio transformer tap changer at line i in } \\
\text { pu. }\end{array}$ \\
\hline$T_{i}^{\max }$ & $\begin{array}{l}\text { Upper ratio transformer tap changer at line i in } \\
\text { pu. }\end{array}$ \\
\hline$N_{t}$ & Number of transformers tap changer. \\
\hline $\begin{array}{l}C_{u p f c_{i}}^{t} \\
\quad C_{u p f c_{i}}\end{array}$ & $\begin{array}{l}\text { Cost of the installation of the UPFC in } \$ / \mathrm{h} \text {. } \\
\text { Cost of the installation of the UPFC in } \$ / \mathrm{kvar}\end{array}$ \\
\hline
\end{tabular}




\begin{tabular}{|c|c|c|c|}
\hline $\bar{I}_{l}^{*}$ & Conjugate current injected in node $\mathrm{i}$ in pu. & $f_{U P F C \cos t}$ & $\begin{array}{l}\text { Objective function equal to the Cost of the } \\
\text { installation of the UPFC in } \$ / \mathrm{h} \text {. }\end{array}$ \\
\hline $\bar{I}_{b}{ }^{*}$ & $\begin{array}{l}\text { Conjugate current in serial part of UPFC } \\
\text { in pu }\end{array}$ & $f_{\text {Losses }}$ & Objective function equal to losses in MW. \\
\hline $\bar{I}_{e}^{*}$ & $\begin{array}{l}\text { Conjugate current in shunt part of UPFC } \\
\text { in pu }\end{array}$ & $n_{\text {upfc }}$ & Number of UPFC. \\
\hline $\bar{S}_{i}^{F}$ & $\begin{array}{l}\text { Complex apparent power injected in } \\
\text { UPFC at node } \mathrm{i} \text { in MW. }\end{array}$ & $N_{p q}$ & Number of load nodes. \\
\hline$P_{i}^{F}$ & $\begin{array}{l}\text { Active power raked from bus } i \text { and } \\
\text { injected in line } i j \text { f UPFC in pu. }\end{array}$ & $f_{D V}$ & $\begin{array}{l}\text { Objective function equal to Voltage Deviation in } \\
\text { pu. }\end{array}$ \\
\hline$Q_{i}^{F}$ & $\begin{array}{l}\text { Reactive power injected at bus } i \text { of UPFC } \\
\text { in MVars }\end{array}$ & $G_{i j}$ & Conductance of line ij in pu. \\
\hline$Q_{j}^{F}$ & $\begin{array}{l}\text { Reactive power injected at bus } j \text { of UPFC } \\
\text { in MVars. }\end{array}$ & $B_{i j}$ & Susceptance of line ij in pu. \\
\hline$S Q_{i}$ & $\begin{array}{l}\text { Operating range of devices UPFC in } \\
\text { MVars. }\end{array}$ & $N$ & Number of sample vectors in NSCE algorithm. \\
\hline$P_{g i}$ & Active power generation in MW & $X_{i}$ & Variables \\
\hline$P_{d i}$ & Active power demand in MW. & $x_{i, j}^{c}$ & \\
\hline$Q_{g i}$ & Reactive power generation in MW & $N(\mu, \sigma)$ & Normal distribution \\
\hline$Q_{d i}$ & Reactive power demand in MW. & $m$ & Number of objective variables. \\
\hline$P_{g i}^{\min }$ & $\begin{array}{l}\text { Lower bound of Active power generation } \\
\text { in MW. }\end{array}$ & $S_{m}\left(X_{i}\right)$ & Sample performance. \\
\hline$P_{g i}^{\max }$ & $\begin{array}{l}\text { Upper bound of Active power generation } \\
\text { in MW. }\end{array}$ & $N . \rho$ & Number of the best samples. \\
\hline$Q_{g i}^{\min }$ & $\begin{array}{l}\text { Lower bound of reactive power generation } \\
\text { in MW. }\end{array}$ & Xelite & The best samples. \\
\hline$\alpha$ & $\begin{array}{l}\text { The factor of repatriation of capital } \\
\text { (FRC). }\end{array}$ & eps & Tolerance in NSCE algorithm. \\
\hline$\gamma_{b}$ & Phase of Serial admittance of UPFC. & NSCE & Non dominated sorting cross entropy. \\
\hline$\gamma_{e}$ & Phase of Shunt admittance of UPFC. & NSGA-II & Elitist non dominated sorting genetic algorithm. \\
\hline$\delta_{i}$ & Phase of voltage at node $\mathrm{i}$ in $\mathrm{pu}$. & $\begin{array}{l}\text { RM- } \\
\text { MEDA }\end{array}$ & $\begin{array}{l}\text { Regularity Model-based Multi-objective } \\
\text { Estimation of Distribution Algorithm. }\end{array}$ \\
\hline$\delta_{j}$ & Phase of voltage at node $\mathrm{j}$ in $\mathrm{pu}$. & UPFC & Unified Power Flow Controller. \\
\hline$\delta_{i j}$ & Difference between $\delta_{i}$ and $\boldsymbol{\delta}_{\boldsymbol{j}}$ in pu. & SVC & Static Var Compensator. \\
\hline$\delta_{b}$ & $\begin{array}{l}\text { Phase of source voltage in serial part of } \\
\text { UPFC in pu. }\end{array}$ & $\begin{array}{l}\text { OPF } \\
\text { ORPF }\end{array}$ & $\begin{array}{l}\text { Optimal Power Flow. } \\
\text { Optimal Reactive Power Flow. }\end{array}$ \\
\hline$\delta_{e}$ & $\begin{array}{l}\text { Phase of source voltage in shunt part of } \\
\text { UPFC in pu. }\end{array}$ & FACTS & Flexible AC transmission system device \\
\hline$\rho$ & Quality ratio in NSCE method. & $\mathrm{CE}$ & Cross Entropy. \\
\hline$\mu$ & Parameter of NSCE algorithm & $\mathrm{LM}$ & Losses Minimization \\
\hline & Standard Deviation in NSCE algorithm. & $\mathrm{DM}$ & Voltage Déviation Minimization \\
\hline LCM & Losses and cost Minimization & DLM & Voltage Déviation with Losses Minimization \\
\hline DCLM & $\begin{array}{l}\text { Voltage Déviation, Cost and Losses } \\
\text { Minimization }\end{array}$ & DCM & Voltage Déviation with Cost Minimization \\
\hline
\end{tabular}

\section{INTRODUCTION}

The industrialization and the growth of the population are the major factors in which the consumption of the electric power increases regularly. Thus, having equilibrium between the production and demand is a challenge, at first sight, it is necessary to increase the number of power stations, the lines and the transformers. However, providing all these constraints involves increased costs and degradation of the natural environment [1], [2].

Controlling the voltage magnitude, active and reactive power in a power system is a very difficult task. This mainly requires active and reactive power injections, subject to minimizing the operating costs [3], [4]. An alternative solution to improve the constraints of power systems is the flexible AC transmission systems (FACTS) devices [5], [6].

The applications of FACTS controller in the power systems was proposed elarlier in [7]. This intelligent device has the capacity to improve many parameters of the power system network such as voltage profile and power-flow control in transmission lines [8]. Several researches have addressed this topic and studied the effects of different types of FACTS devices in power systems such as the static var compensator (SVC) as reported in [9]-[10].

The unified power flow controller (UPFC) is another topic of interest, in [6] an optimal location and parameter setting of UPFC for enhancing power system security based on differential evolution algorithm 
was proposed. Literature reveals that many algorithms have been developed for the OPF incorporating the UPFC devices. For instance: in [11] sensitivity based approach to find a suitable placement of UPFC was proposed.

The state-of-the-art UPFC analyses primarily focus on the application of stability control in power systems as reported in [12], [13]. Some studies have attempted to solve the optimal location of UPFCs with respect to different methods as reported in [14], [15]. Evolutionary-programming-based load flow algorithm, genetic algorithm (GA) and particle swarm optimization (PSO) were proposed for solving the OPF problem of UPFC [16]-[18]. Find the optimal location of the UPFC device in the power system with the appropriate parameter setting is difficult, since it can be installed in different locations; moreover, its efficiency is different from one place to another. For this reason, some attempts have been developed including contingency selection methods [19]-[21], deferential evolution (DE) [22], [23], and NSGA-II [24]-[27].

Recently, a new type of heuristic algorithm, the so-called NSCE method has been developed and applied in solving complex optimization problems [28], [29]. It has been applied to handle with several engineering problems [30]-[32]. In the present study, a novel algorithm based on NSCE method is used. The proposed algorithm use both of the technique of elitist non dominated sorting and the cross entropy methodology in order to enhance the solution quality to find out the optimal location and parameter setting of UPFC device for enhancing the power flow system.

The CE method is one of the Monte carlo techniques. The motivation behind the use of the NSCE is because it employs the importance sampling approach (IS) which confer it the ability to deal with large scale problems with poor simulation tools. CE methods are suitable for problems when other techniques are too difficult to solve or presents a high computation time.

Find an optimal number of UPFC in a network in order to satisfy the power demand in an electrical network with fewer losses is the maincontribution of this study. For this purpose, in this study, one kind of FACTS devices is used namely: UPFC. In which, the number of UPFC installed in the network is varied. The remaining parts of this paper are organized as follows: Section 2 develops the UPFC modeling. In Section 3, problem formulation for the OPF problem considering non-convex cost functions, and other technical constraints. The proposed NSCE approach is described in the section 4. Case studies and numerical results are elaborated in the Section 4, and finally, conclusionis given in Section 5.

\section{UPFC MODELLING}

The UPFC can provide simultaneous control of all basic power system parameters (transmission voltages, impedances and phase angles). The controller can full functions of reactive shunt compensation, series compensation and phase shifting meeting multiple control objectives. From a functional perspective, the objectives are met by applying a boosting transformer injected voltage and an exciting transformer reactive current. The injected voltage is inserted by series transformer.

Shows the equivalent circuit of a UPFC power flow model in the Figure 1. This model consists of two coordinated synchronous voltage sources represent the UPFC [33]. First, a converter is connected in shunt and the second one in series with the line. The shunt converter is primarily used to provide active power demand of the series converter.

The first converter can generate or absorb reactive power, if it is desired, and provide independent shunt reactive compensation for the line. The second converter provides the main function of the UPFC by injecting a voltage with controllable magnitude and phase angle in series with the line via a voltage source. The most suitable electric model with the physical behavior of the UPFC is presented in the Figure 2.

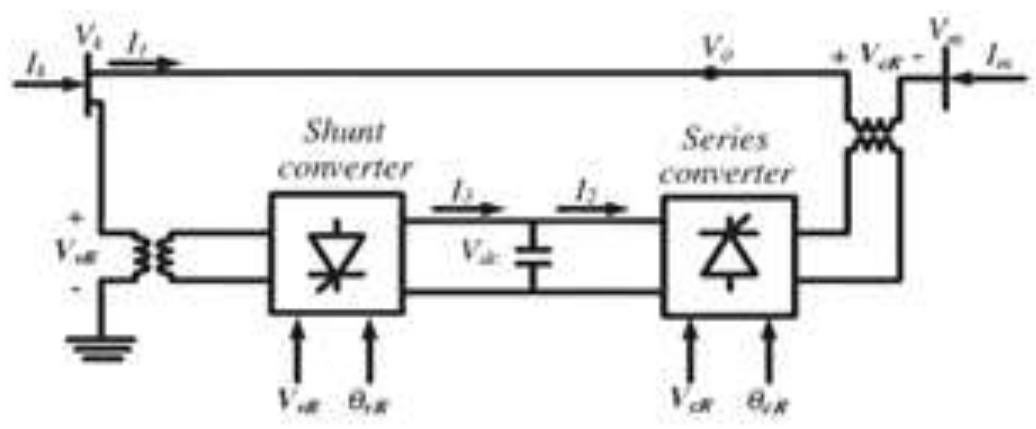

Figure 1. UPFC installed in power system 
The simplified electrical model is shown in Figure 2.

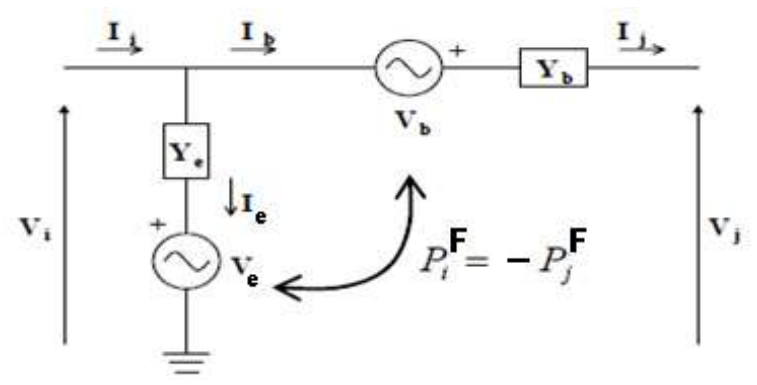

Figure 2. UPFC equivalent circuit

The standard notation is:

$\bar{V}_{i}=V_{i} e^{j \delta_{i}} ; \bar{V}_{j}=V_{j} e^{j \delta_{j}} ; \bar{Y}_{e}=Y_{e} e^{j \gamma_{e}} ; \bar{Y}_{b}=Y_{b} e^{j \gamma_{b}}$

The injected powers at the busses $\mathrm{i}$ and $\mathrm{j}$ respectively are [34]:

$\bar{S}_{i}=\bar{V}_{l} \bar{I}_{l}^{*}$

$\bar{S}_{i}=\bar{V}_{l} \bar{I}_{b}^{*}+\bar{V}_{l} \bar{I}_{e}^{*}$

$\bar{S}_{i}=\bar{V}_{l} \bar{Y}_{b}^{*}\left(\bar{V}_{l}^{*}+{\overline{V_{b}}}^{*}-\bar{V}_{J}^{*}\right)+\bar{V}_{l} \bar{Y}_{e}^{*}\left(\bar{V}_{l}^{*}-\bar{V}_{e}^{*}\right)$

$\bar{S}_{i}=V_{i}^{2}\left({\overline{Y_{b}}}^{*}+\bar{Y}_{e}^{*}\right)-\bar{V}_{l} \bar{V}_{J}^{*} \bar{Y}_{b}^{*}+\bar{V}_{l}\left(\bar{Y}_{b}^{*}{\overline{V_{b}}}^{*}-\bar{Y}_{e}^{*} \bar{V}_{e}^{*}\right)$

$\bar{S}_{j}=\bar{V}_{J} \bar{I}_{J}^{*}=-\bar{V}_{J} \bar{I}_{b}^{*}$

$\bar{S}_{j}=-\bar{V}_{J} \bar{Y}_{b}^{*}\left(\bar{V}_{l}^{*}+{\overline{V_{b}}}^{*}-\bar{V}_{J}^{*}\right)$

$\bar{S}_{j}=V_{j}^{2} \bar{Y}_{b}^{*}-\bar{V}_{J} \bar{V}_{b}^{*} \bar{Y}_{b}^{*}-\bar{V}_{J} \bar{V}_{l}^{*} \bar{Y}_{b}^{*}$

The most convenient approach for incorporating (1) and (5) into the load flow equations identifies additional injections $\left(\bar{S}_{i}^{F}, \bar{S}_{j}^{F}\right)$ according to internal variables of the UPFC $\left(\bar{V}_{b}\right.$ et $\left.\bar{V}_{e}\right)$ and the admittances of transformer $\bar{Y}_{e}$ and $\bar{Y}_{b}[34]$.

The mathematic expressions are:

$$
\begin{aligned}
& \bar{S}_{i}^{F}=\bar{V}_{l}\left(\bar{Y}_{b}^{*}{\overline{V_{b}}}^{*}-\bar{Y}_{e}^{*} \bar{V}_{e}^{*}\right)=P_{i}^{F}+j Q_{i}^{F} \\
& \bar{S}_{j}^{F}=-\bar{V}_{J}{\overline{V_{b}}}^{*} \bar{Y}_{b}{ }^{*}=P_{j}^{F}+j Q_{j}^{F} \\
& P_{i}^{F}=-P_{j}^{F}
\end{aligned}
$$

Where :

$$
\begin{aligned}
& P_{i}^{F}=V_{i} V_{b} Y_{b} \cos \left(\delta_{i}-\delta_{b}-\gamma_{b}\right)-V_{i} V_{e} Y_{e} \cos \left(\delta_{i}-\delta_{e}-\gamma_{e}\right) \\
& P_{j}^{F}=-V_{j} V_{b} Y_{b} \cos \left(\delta_{j}-\delta_{b}-\gamma_{b}\right) \\
& Q_{i}^{F}=V_{i} V_{b} Y_{b} \sin \left(\delta_{i}-\delta_{b}-\gamma_{b}\right)-V_{i} V_{e} Y_{e} \sin \left(\delta_{i}-\delta_{e}-\gamma_{e}\right) \\
& Q_{j}^{F}=-V_{j} V_{b} Y_{b} \sin \left(\delta_{j}-\delta_{b}-\gamma_{b}\right)
\end{aligned}
$$


Such as:

$P_{i}^{F}$ : Active power raked from bus $i$ and injected in line $i j$ of UPFC.

$Q_{i}^{F}$ : Reactive power injected at bus $i$ of UPFC.

$Q_{j}^{F}$ : Reactive power injected at bus $j$ of UPFC.

The model of injection is shown in the Figure 3:

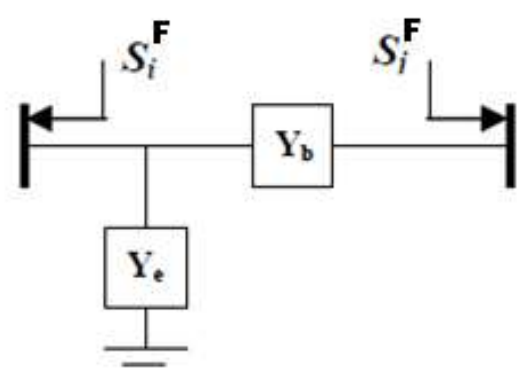

Figure 3. Model of injection of UPFC

\section{PROBLEM FORMULATION}

The main goal of the present study is to minimize the cost of power supplies injected by the UPFC and the transmission power losses. The main in objective functions are given as follow:

\subsection{Cost of the UPFC supplies power}

The objective function representing the cost of the UPFC installation is given as follow [35];

$$
\begin{aligned}
& f_{U P F C c o s t}=\sum_{i=1}^{n_{u p f c}} C_{u p f c_{i}}^{t} \\
& C_{u p f c_{i}}^{t}=\left(C_{u p f c_{i}} \times S Q_{i} \times 1000 \times \propto\right) / 8760 \\
& C_{u p f c_{i}}=0.0003 \times S Q_{i}{ }^{2}-0.2691 \times S Q_{i}+188,22 \\
& \propto=\frac{r(1+r)^{n}}{(1+r)^{n}-1} \\
& S Q_{i}=\sum\left(\left|Q_{i}^{F}\right|+\left|Q_{j}^{F}\right|\right), i=1 \ldots n_{u p f c}
\end{aligned}
$$

where:

$S Q_{i}$ : Operating range of devices UPFC in MVAR.

$C_{u p f c_{i}}^{t}$ : Cost of the installation of the UPFC in $\$ / \mathrm{h}$.

$C_{u p f c_{i}}$ : Cost of the installation of the UPFC in $\$ / \mathrm{kvar}$

$\propto:$ The factor of repatriation of capital (FRC).

$r$ : The interest rate.

$n$ : The period of repatriation of capital.

\subsection{Total transmission active losses}

The total losses in the transmission lines are given by the follow expression [35]:

$$
f_{\text {Losses }}=P_{\text {LosS }}=\sum_{i=1}^{N_{g}} P_{g_{i}}-\sum_{i=1}^{N_{p q}} P_{c_{i}}
$$

Where: $n_{g}$ is the number of generator buses and $n_{p q}$ is the number of load buses.

\subsection{Voltage deviation}

The voltage deviation function is given by the follow expression [35]:

Indonesian J Elec Eng \& Comp Sci, Vol. 22, No. 2, May 2021 : 648 - 659 


$$
f_{D V}=\sum_{i=1}^{i=N_{p q}}\left|V_{i}-1\right|
$$

\subsection{Equality constraints}

These constraints represent the typical load flow equations as follows:

$$
\begin{aligned}
& P_{g i}-P_{d i}-V_{i} \sum_{j=1}^{N b u s} V_{J}\left(G_{i j} \cos \delta_{i j}+B_{i j} \sin \delta_{i j}\right)=0 \\
& Q_{g i}-Q_{d i}-V_{i} \sum_{j=1}^{N b u s} V_{J}\left(G_{i j} \sin \delta_{i j}-B_{i j} \cos \delta_{i j}\right)=0
\end{aligned}
$$

Where: $P_{g i}$ and $P_{d i}$ are active power generation and demand respectively, $Q_{g i}$ and $Q_{d i}$ are the reactive power generation and demand respectively.

\subsection{Inequality constraints}

The inequality constraints representing the system operating limits could be expressed as follows;

- The upper and the lower bounds on the active generations,

$$
P_{g i}^{\min } \leq P_{g i} \leq P_{g i}^{\max }, i=1 \ldots, N_{G}
$$

- The upper and lower bounds on the active power generations,

$$
Q_{g i}^{\min } \leq Q_{g i} \leq Q_{g i}^{\max }, i=1 \ldots, N_{g}
$$

- The upper and lower bounds on the voltage generations,

$$
V_{g i}^{\min } \leq V_{g i} \leq V_{g i}^{\max }, i=1 \ldots, N_{g}
$$

- The upper and lower transformer tap setting transformer limits. This variable is discrete and can have 27 positions.

$$
T_{i}^{\min } \leq T_{i} \leq T_{i}^{\max }, i=1 \ldots, N_{t}
$$

\section{NSCE (NON-DOMINATED SORTING CROSS ENTROPY)}

The CE method, pioneered by Rubinstein in 1997 as a stochastic learning algorithm for estimating probabilities of rare events, has been broadened as a generic and efficient tool for solving difficult numerical and NP-hard combinatorial optimization problems. The NSCE algorithm is an extension of the $\mathrm{CE}$ from the single objective optimization to the multi-objective optimisation where his elitism mechanism is based on the non-dominated sorting [25].

a) Initialize algorithm parameters, like means $(\mu)$ and standard deviations $(\sigma)$ of $p d f$ 's, sample size $N$, and the quality ratio $\rho$.

b) Generate $N$ sample vectors $X_{i}, \mathrm{i}=1, \ldots, N$ as: $\mathrm{x}_{\mathrm{i}, \mathrm{j}}^{\mathrm{c}} \sim N(\mu, \sigma)$ following the normal distribution, $i=1, \ldots, N ; j=1, \ldots, \mathrm{m}$.

where $N()$ produces the normal distributed random numbers and $m$ defines the number of objective variables.

c) Compute sample performances $S_{m}\left(X_{i}\right), i=1, \ldots, \mathrm{N}$.

d) Sorting the samples based on the non dominance criterion [25], and select only the best $N . \rho$ Samples Xelite.

e) Determine next pdf's parameters based on the Xelite:

$$
\mu=\sum_{N \rho} X_{\text {elite }} /(N \rho) . \sigma=\sum_{N \rho}\left(X_{\text {elite }}-\mu\right)^{2} /(N \rho-1) .
$$

f) Check if stopping criterion is met, for example: if maximum iteration count is exceeded or $p d f$ parameters are below the tolerance value eps. If yes, then output the best-so-far sample and terminate, otherwise go to step 2.

At the end of each iteration, non-dominated solutions explored within each cluster are combined together and reclustered before the next iteration starts. This way, distribution of non-dominated solutions 
along the pareto front become more uniform because solutions found starting from a particular cluster may cross border and belong to neighbour cluster.

As the first step in the algorithm is the generation of the initial population. In the present study, the population is formulated by the parameters of the power flow. It is noticeable that the population size is decided according to the dimension of the problem at hand. The next step is the generation of the initial population; at this step all the involved constraints should be verified. The final solution set is the Pareto set.

\section{RESULTS AND DISCUSSION}

In the majority of the research the UPFC devices are limited to one in the entire electrical network. However, in order to make the system more reliable and close to the reality, the number of the UPCF can take more than one in the electrical network. The main reason of this choice is to ensure a good stability and minimum power losses.

The range of variation of the reactive power injected by the UPFC is considered of \pm 100 MVAR out of the two nodes upstream and downstream of the branch where the UPFC is installed. The data of the UPFC are [24]: $x_{b}=0.1 \mathrm{pu}$ and $\mathrm{y}_{\mathrm{e}}=10 \mathrm{pu}$.Since the NSCE technique is stochastic, their parameters and the adopted values were found by trail and errors to give the best performance in the most cases study.

\subsection{Test system: IEEE 30 bus system}

This network contains 6 generating units, 41 branches, 4 transformers and 5 nodes of generation [36]. The bus one is chosen as the slack bus. The voltage magnitude limits of the generating units busses are taken between 0.94 p.u and 1.06 p.u. Where these limits are taken between 0.9 p.u and 1.1 p.u. for the demand busses. The limits on the turn ratios of the transformers are 0.90 and 1.10 for all tests, which means that positions are between 1 and 27.The IEEE 30 bus is modified by inserting 10 UPFC.

\section{Case 01: Losses minimization (LM)}

In this case, the cross entropy (CE) is employed for the minimization of losses. A convergence is reached after 3000 iteration, according to the Figure 4 the minimum value is $3.02208 \mathrm{MW}$.

\section{Case 02: Voltage déviation minimization (DM)}

The voltage deviation is introduced in this case. As seen in the Figure 5, the minimum attainable value by $\mathrm{CE}$ is $0.08148 \mathrm{pu}$ which is obtained by solution of the reactive power system compensation problem considering the voltage deviation as the unique objective function.

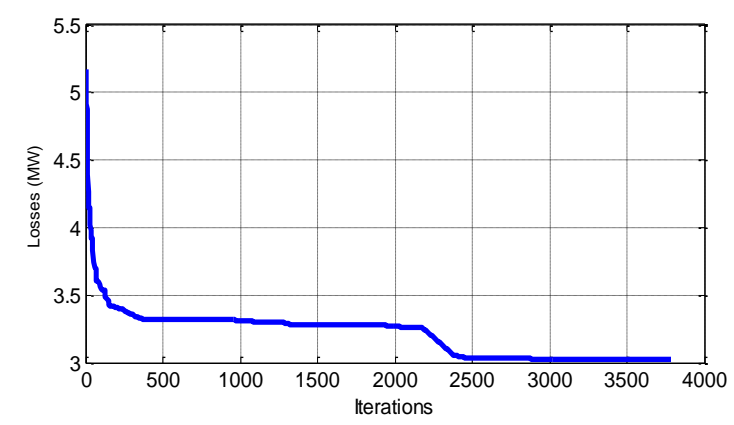

Figure 4. Active power losses minimization

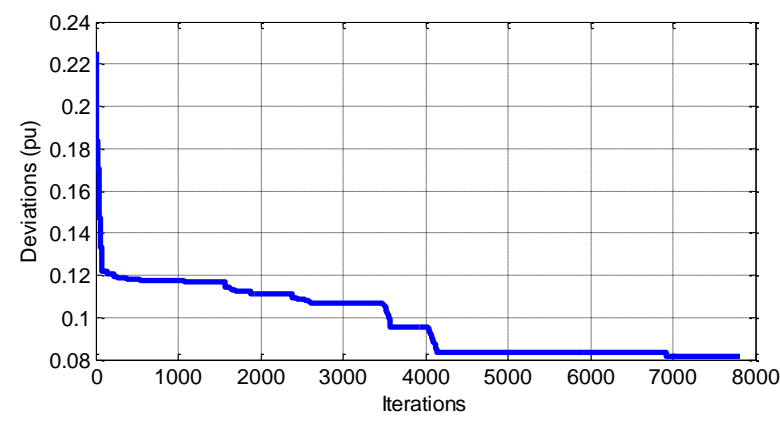

Figure 5. The voltage deviations minimization

\section{Case 03: Voltage déviation with losses minimization (DLM)}

In this case of study, the voltage deviation and the active power losses are considered, using the NSGA-II, RM-MEDA and NSCE to search the set of solutions with 600 members.

The best solution is obtained for the voltage deviation and the active power losses is given together with the values of the control variables resulting from the power flow in Table 1 . The convergence of the Pareto solution is given in the Figure 6(a), Figure 6(b), Figure 6(c) and Figure 6(d).

By NSGA-II, first we have chosen 10 possible locations of UPFC, but all results give only 4 UPFCs for the optimal solutions. We have obtained 2 sets of solutions, one is $(0,33,56,64)$ and the second is $(1,9$, 56, 72) as shown in Figure 6(a). These numbers represent the number of lines which the UPFCs should be 
installed. We note that the total number of lines is 41 , so if the number of line exceed 41 (for example 56) that means the UPFC should be installed in the line $15(56-41=15)$ but from the end of line.

Then, we apply RM-MEDA with increasing the number of UPFC to 6, in the Pareto front shown in Figure 6(b), it is illustrated that new solutions are obtained such as $(1,33,56,64)$. In Figure 6(c), we have further solutions located in the midlle of the pareto front by applying nsce. Finally, we apply consequently each method (nsga-ii, rm-meda and nsce) after a grand number of generations (iterations) to obtain better result as shown in Figure 6(d).

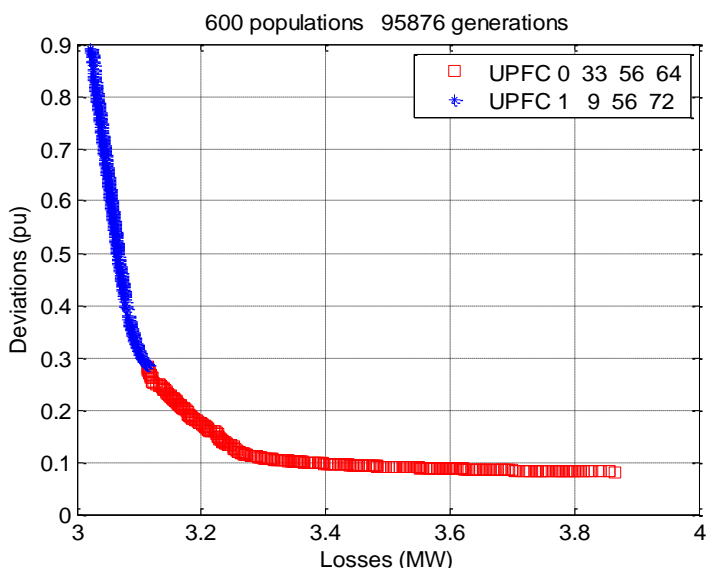

Figure 6(a). The pareto of deviation-losses minimization by NSGA-II

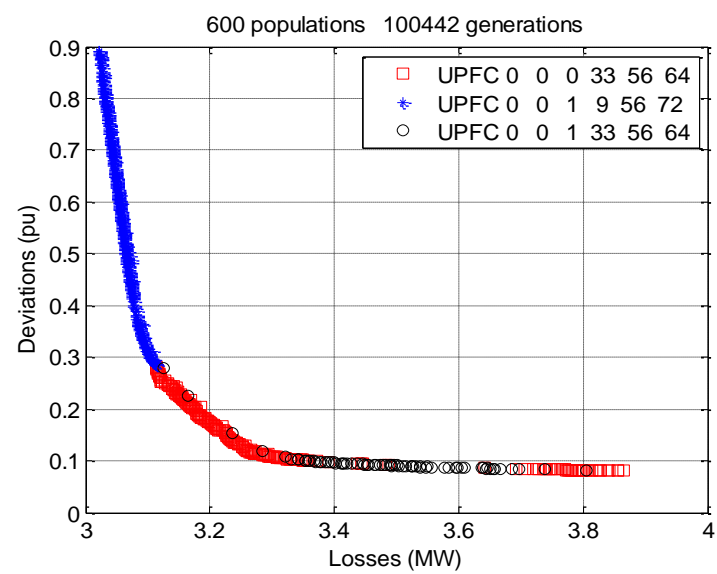

Figure 6(c). The pareto of deviation-losses minimization by NSCE

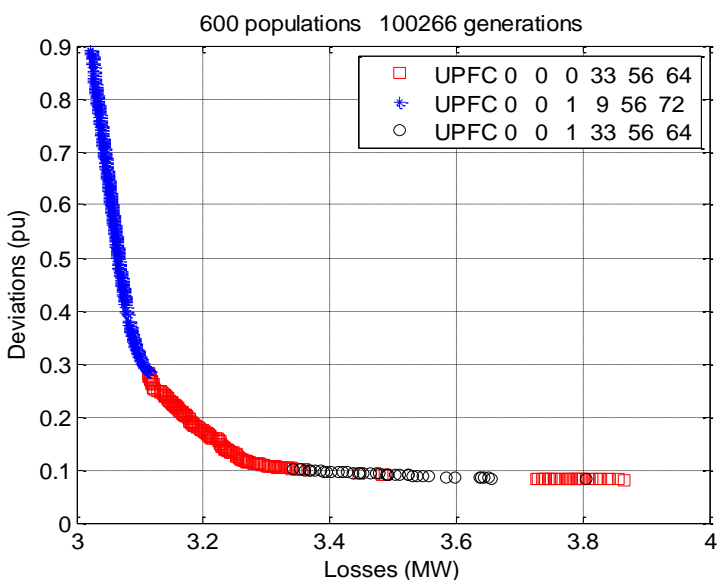

Figure 6(b). The pareto of deviation-losses minimization by RM-MEDA

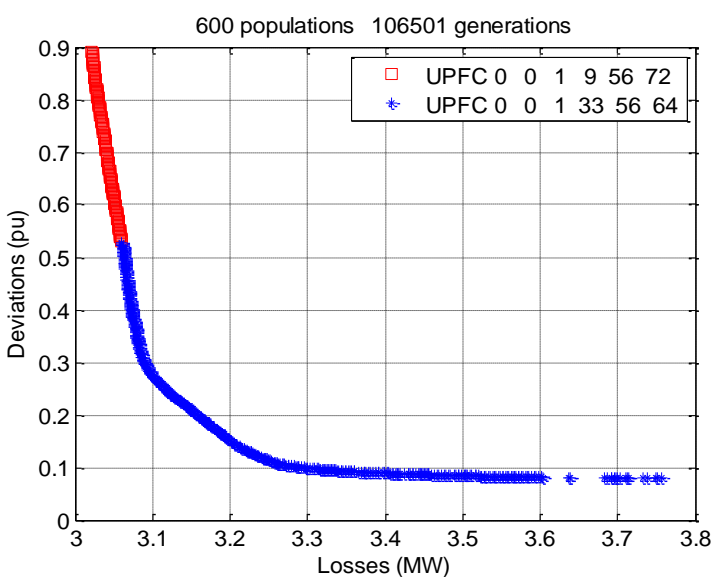

Figure 6(d). The pareto of deviation-losses minimization by NSCE, RM-MEDA and NSGA-II

We can see that the solution $(0,33,56,64)$ is completely removed from the Pareto front and replaced by $(\mathbf{1}, 33,56,64)$.

\section{Case 04: Voltage déviation with cost minimization (DCM)}

In the Figure 7 and 8, the Pareto solution is shown about Voltage deviation and cost of UPFC simultaneously.

\section{Case 05: Losses and cost minimization (LCM)}

For this case, the losses and the fuel cost are optimized simultaneously. The best solution is obtained for the losses and the fuel cost is given in Table 1. From the Figure 9, it can be seen that the Pareto optimal solution I ensured using the NSCE, NSGA-II and RM-MEDA methods. 


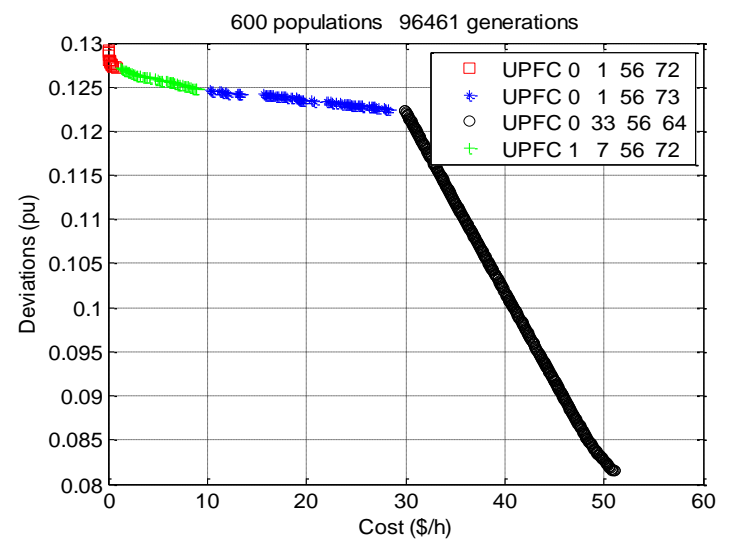

Figure 7. The pareto of deviation-cost minimization by NSGA-II

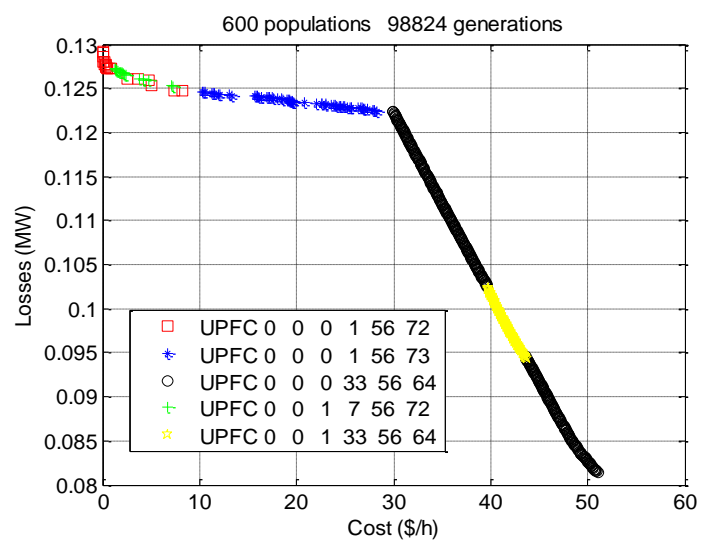

Figure 8 . The pareto of deviation-cost minimization by NSCE

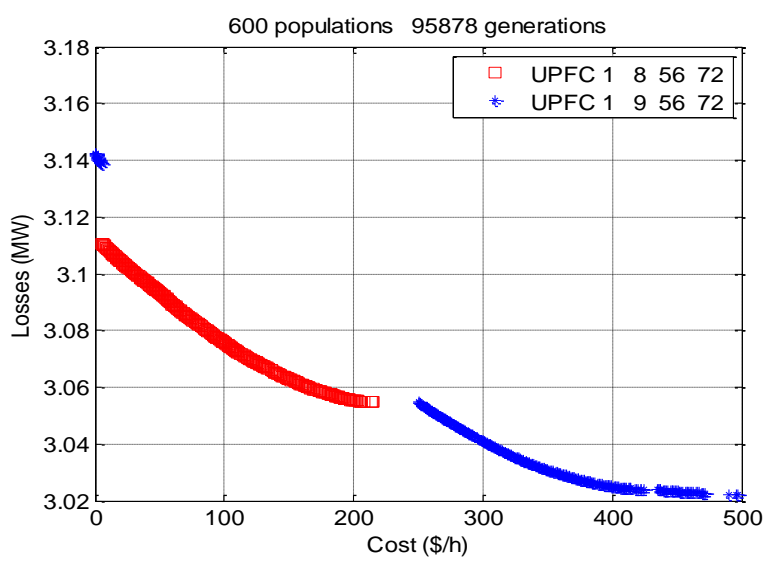

Figure 9. The pareto of losses-cost minimization by NSCE, NSGA-II and RM-MEDA

\section{Case 06: Voltage déviation, cost and losses minimization (DCLM)}

In this case, three objective functions are considered, namely: the voltage deviation, the cost and the active power losses. All methods are applied successively. According to Figure 10, it stands to reason that the proposed algorithm not only converges to a lower fuel cost for solving Case 1 but also reduces the losses of power and the voltage deviations.

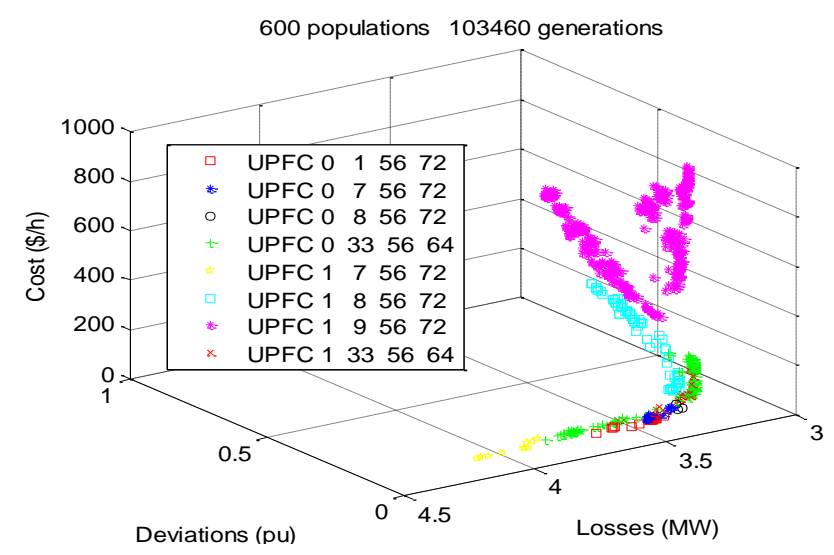

Figure 10. The pareto of cost-deviation-losses minimization by all methods 
In Table 1, $(\mathrm{r}, \mathrm{s})$ are the nodes which connect the line where the UPFC is installed. With applying NSCE, the optimal deviation voltage is 0.08096 p.u compared to 0.081481 obtained by NSGA-II. Finally, the results show that the choice of the lines candidates to the compensation for the various considered cases carries practically on the same branches for the minimization of losses and on other branches for the minimization of deviation but shares on two branches 1 and 56.

Table 1. Optimal results

\begin{tabular}{|c|c|c|c|c|c|}
\hline Variables & $\begin{array}{c}\text { DM\& CDM } \\
\text { (NSGA-II) }\end{array}$ & $\begin{array}{c}\text { DM\& CDM } \\
\text { (NSCE) }\end{array}$ & $\begin{array}{l}\text { LM\& CLM } \\
\text { All methods }\end{array}$ & $\begin{array}{c}\text { CDM } \\
\text { All methods }\end{array}$ & $\begin{array}{c}\text { CLM } \\
\text { All methods }\end{array}$ \\
\hline UPFC_1(r,s) & 0 & $1(1.2)$ & $1(1.2)$ & 0 & $1(1.2)$ \\
\hline UPFC_2(r,s) & $33(24.25)$ & $33(24.25)$ & $9(6.7)$ & $1(1.2)$ & $9(6.7)$ \\
\hline UPFC_3(r,s) & $56(12.4)$ & $56(12.4)$ & $56(12.4)$ & $56(12.4)$ & $56(12.4)$ \\
\hline UPFC_4(r,s) & 64(19.18) & 64 (19.18) & $72(24.22)$ & $72(24.22)$ & $72(24.22)$ \\
\hline$P_{i n j i}(1)(p u)$ & 0 & 0 & 0.1323 & 0 & 0.1092 \\
\hline$Q_{\text {inji }}(1)(p u)$ & 0 & -0.0004 & 0.0087 & 0 & 0 \\
\hline$Q_{\text {injj }}(1)(p u)$ & 0 & 0.0064 & 0.0278 & 0 & 0 \\
\hline$P_{i n j i}(2)(p u)$ & -0.0910 & -0.0829 & 0.0150 & 0.1248 & 0.0143 \\
\hline $\mathrm{Q}_{\text {inji }}(2)(\mathrm{pu})$ & 0.0001 & -0.0048 & 0.2528 & 0 & 0 \\
\hline$Q_{\text {injj }}(2)(p u)$ & 0 & 0.0029 & 0.1338 & 0 & 0 \\
\hline $\mathrm{P}_{\mathrm{inji}}(3)(\mathrm{pu})$ & 0.7490 & 0.737 & 0.6958 & 0.9809 & 0.6375 \\
\hline$Q_{\text {inji }}(3)(p u)$ & 0.0004 & -0.0042 & 0.3081 & 0 & 0 \\
\hline$Q_{\text {injj }}(3)(p u)$ & -0.0001 & -0.0063 & -0.0032 & 0 & 0 \\
\hline$P_{i n j i}(4)(p u)$ & -0.0155 & -0.0232 & 0.0345 & -0.0689 & 0.0064 \\
\hline$Q_{\text {inji }}(4)(p u)$ & 0.1108 & 0.1192 & -0.0458 & 0 & 0 \\
\hline$Q_{\text {injj }}(4)(p u)$ & 0.0770 & 0.0743 & -0.0056 & 0 & 0 \\
\hline $\mathrm{Vg} 1(\mathrm{pu})$ & 0.99873 & 0.99566 & 1.05000 & 1.00640 & 1.04999 \\
\hline $\mathrm{Vg} 2(\mathrm{pu})$ & 0.99877 & 1.00393 & 1.05000 & 1.01023 & 1.04999 \\
\hline Vg5(pu) & 1.01884 & 1.01823 & 1.03531 & 1.01100 & 1.03100 \\
\hline $\mathrm{Vg} 8(\mathrm{pu})$ & 1.00961 & 1.00905 & 1.03656 & 1.00311 & 1.03829 \\
\hline $\operatorname{Vg} 11(\mathrm{pu})$ & 0.99709 & 0.99704 & 1.04707 & 1.04843 & 1.04999 \\
\hline $\mathrm{Vg} 13(\mathrm{pu})$ & 1.04997 & 1.04936 & 1.04998 & 1.04995 & 1.04999 \\
\hline $\mathrm{T}\left(6 \_9\right)$ & 15 & 15 & 12 & 22 & 24 \\
\hline $\mathrm{T}\left(6 \_10\right)$ & 4 & 4 & 2 & 2 & 4 \\
\hline $\mathrm{T}\left(4 \_12\right)$ & 13 & 13 & 13 & 8 & 14 \\
\hline $\mathrm{T}\left(28 \_27\right)$ & 8 & 8 & 9 & 8 & 12 \\
\hline Active Power Losses (MW) & 3.86458 & 3.75692 & 3.02208 & 3.50305 & 3.14229 \\
\hline Voltage Deviation (pu) & 0.08148 & 0.08096 & 0.89162 & 0.12916 & 0.32618 \\
\hline Cost of the UPFCs $(\$ / \mathrm{h})$ & 51.0926 & 71.5979 & 496.588 & 0 & 0 \\
\hline
\end{tabular}

The proposed NSCE provides a well-distributed pareto front (cost/losses/deviation) for different cases study especially when it is supported by other methods like NSGA-II and M-MEDA. The application of the NSCE, NSGA-II and RM-MEDA offers various proposals for solutions to the problem (minimization of power losses, deviation voltages and UPFC cost) since the equality and the inequality constraints are satisfied. The proposed NSCE method is good in temrs of accuracy and robustness.

\section{CONCLUSION}

In the present study, the effectiveness of the optimal installation of UPFC for enhancing the security of the power system has been investigated. NSCE method has been successfully applied to the problem at hand. In order to show the merit of the proposed NSCE, two methods were used namely, NSGA-II and RMMEDA. The improvement of the obtained results is insured by progress periodically two other algorithms NSGA-II and RM-MEDA. The application carried out on the model network IEEE 30 bus system, in which, the three methods provide a well distributed Pareto front for all the cases study. The contribution of the $\mathrm{UPFC}$ on the losses minimization is efficient in the increasing in the transmission capacity of the lines.

\section{ACKNOWLEDGMENTS}

We would like to thank the General Directorate of Scientific Research and Technology Development in Algeria (Direction Générale de la Recherche Scientifique et de Développement Technologique 'DGRSDT' algerie) for the ressources proveded for scientific research and development. 


\section{REFERENCES}

[1] G. A. M. Hosaini Hajivar, S. S. Mortazavi, "Impact of Shunt FACTS Devices on Security Constrained Unit Commitment," 2016, 5, pp. 22-39, doi: 10.11591/ijape.v5.i1.pp22-39.

[2] Pramod Kumar Gouda, Prakash Kumar Hota, "Impact of FACTS Devices in Optimal Generation in Deregulated Power System," International Journal of Applied Power Engineering (IJAPE), pp. 118-125, 2015.

[3] Devaraj, D., Preetha Roselyn, J., "Genetic algorithm based reactive power dispatch for voltage stability improvement," Int. J. Electri. Power Energy Syst, vol. 32, no. 10, pp. 1151-1156, 2010, doi: 10.1016/j.ijepes.2010.06.014.

[4] Chaohua, D., Weirong, C., Yunfang, Z., Xuexia, Z., "Reactive power dispatch considering voltage stability with seeker optimization algorithm," Electr Power Syst Res, vol. 79, no. 10, 2009, pp. 1462-1471, doi: 10.1016/j.epsr.2009.04.020.

[5] Benaouda, O.F., Benbi abdellah, A., Cherif, B.D.E., "Diagnosis Method for GTO Open Switch Fault Applied to Reconfigurable Three-Level 48-Pulse STATCOM," Power engineering and electrical engineering, vol. 17, no. 2, 2019, pp. 114-126, doi: 10.15598/aeee.v17i2.3192.

[6] Sai Ram Inkollu, Venkata Reddy Kota, "A Multi - ObjectiveHybrid Heuristic Approach for Optimal Setting of FACTS Devices in Power System Operation," International Journal of Applied Power Engineering (IJAPE), pp. 120-129, 2016, doi: 10.11591/ijape.v5.i3.pp120-129.

[7] Sushmit Mazumdar, Kaushik Basu, "Hardware emulation of energization of a long transmission line by high frequency electronic converter," IEEE transactions on power electronics, vol. 35, no. 9, 2020, pp. 9267-9280, doi: 10.1109/TPEL.2020.2973543.

[8] Venkateswara Rao, B., Nagesh Kumar, G.V., "Optimal power flow by BAT search algorithm for generation reallocation with unified power flow controller," Electrical Power and Energy Systems, vol. 68, no. 1, 2015, pp. 81-88, doi: 10.1016/j.ijepes.2014.12.057.

[9] Dash, PK., Das, S., Moirangthem, J., "Distance protection of shunt compensated transmission line using a sparse Stransform," IET Gen Transm Distrib, vol. 9, no. 12, 2015, pp. 1264-1274, doi: 10.1049/iet-gtd.2014.1002.

[10] Ghorbani A, Mozafari B, Khederzadeh, M., "Impact of SVC on the protection of transmission lines," Int J Electr Power Energy Syst, vol. 42, no. 1, pp. 702-9, 2012, doi: 10.1016/j.ijepes.2012.04.029.

[11] Singh SN, Erlich I., "Locating unified power flow controller for enhancing power system loadability," In: Int conf future power system, vol. 42, no. 1, 2005, pp. 1-5, doi: 10.1109/FPS.2005.204219.

[12] Ghofrani, M., Etezadi-Amoli, M., Fadali, M.S., Moeini-Aghtaie, M., "A Multi-Objective Transmission Expansion Planning Framework in Deregulated Power Systems With Wind Generation," IEEE transaction on power systems, vol. 29, no. 6, 2014, pp. 1-10, doi: 10.1109/TPWRS.2014.2316529.

[13] Ibrahim B. M. et all., "Optimal reactive power resources sizing for power system oprations enhancement based on improved grey wolf optimizer," IET GTD, vol. 12, no. 14, 2018, pp 3121-3434, doi: 10.1049/iet-gtd.2018.0053.

[14] Taher SA, Akbari S, Abdolalipour A, Hematti R. "Robust decentralized controller design for UPFC using 1synthesis," Commun Nonlinear Sci Numer Simul, vol. 15, pp. 2149-61, 2010, doi: 10.1016/j.cnsns.2009.08.006.

[15] Fang WL, Ngan HW., "Optimizing location of unified power flow controllers using the method of augmented Lagrange multipliers," IEE Proc Gener Transm Distrib, vol. 146, no. 5, pp. 428-34, 1999, doi: 10.1049/ipgtd:19990507.

[16] Wang, KP, Yurevich J, Li, A., "Evolutionary-programming-based load flow algorithm for systems containing unified power flow controllers," IEE Proc Gener Transm Distrib, vol. 150, no. 4, pp. 441-446, 2003, doi: 10.1049/ip-gtd:20030405.

[17] Arab khaburi, D., Kazemi, A., Yari, M., Aghaei J., "Optimal placement of UPFC in power systems using genetic algorithm," In: IEEE int conf industrial technology, pp. 1694-1699, 2006, doi: 10.1109/ICIT.2006.372474.

[18] Saravanan M, et al., "Application of PSO technique for optimal location of FACTS devices considering system loadability and cost of installation," Power Engineering Conf, 2005, pp. 716-21, doi: 10.1109/IPEC.2005.207001.

[19] Matavalam, A. R. R., Ajjarapu, A., "PMU-Based monitoring and mitigation of delayed voltage recovery using admittances," IEEE Trans Power Syst, vol. 34, no. 6, 2020, pp. 4451-4463, doi: 10.1109/PESGM41954.2020.9281803.

[20] Sobajic, D., Pao, Y., "An artificial intelligence system for power system contingency screening," IEEE Trans Power Syst, vol. 3, no. 2, pp. 647-53, 1988.

[21] Duong, T.L. et all., "A new method for secured optimal power flow under normaland network contingencies via optimal location of TCSC," Int J, elect power energy syst, vol. 52, pp. 68-80, 2013, doi: 10.1016/j.ijepes.2013.03.025.

[22] Sudersan, A., Abdelrahman, M., Radman, G., "Contingency selection and static security enhancement in power systems using Heuristics-based genetic Algorithms," In: IEEE proc thirty-sixth southeastern symposium, 2004, pp. 556-560, doi: 10.1109/SSST.2004.1295720.

[23] Shaheen Husam, I., Rashed Ghamgeen, I., Cheng, S.J., "Optimal location and parameter setting of UPFC for enhancing power system security based on differential evolution algorithm," Electr. Power Energy Syst, vol. 33, no. 1, pp. 94-105, 2011, doi: 10.1016/j.ijepes.2010.06.023.

[24] Krishnam Naidu, R.S.R., Venkateswara Rao, M., "An approach for optimal placement of UPFC to enhance voltage stability,” Int. J. Appl. Innov. Eng.Manage., pp. 307-313, 2013.

[25] Deb, K., Jain, H., "An evolutionary many-objective optimization algorithm using reference-point based nondominated sorting approach, partI, solving problems with box constraints," Evolutionary Computation, IEEE Transaction, vol. 18, pp. 577-601, 2014, doi: 10.1109/TEVC.2013.2281535. 
[26] Al Rashidi, M. R., El-Hawary, M. E, "Hybrid Particle Swarm Optimization Approach for Solving the Discrete OPF Problem Considering the Valve Loading Effects," IEEE transaction on power systems, vol. 22, no. 4, pp. 20302038, 2007, doi: 10.1109/TPWRS.2007.907375.

[27] Cheng-Jin Ye and Min-Xiang Huang, "Multi-Objective Optimal Power Flow Considering Transient Stability Based on Parallel NSGA-II," IEEE Transaction on power systems, vol. 30, no. 2, 2014, pp. 857-866, doi: 10.1109/TPWRS.2014.2339352.

[28] Gerbex S, Cherkaoui R, Germond AJ., "Optimal location of multi-type FACTS devices in a power system by means of genetic algorithms," IEEE Trans Power Syst, vol. 16, no. 3, 2001, pp. 537-44, doi: 10.1109/59.932292.

[29] Rubinstein RY., "Optimization of computer simulation models with rare events," Eur J Oper Res, vol. 99, no. 1, 1997, pp. 89-112, doi: 10.1016/S0377-2217(96)00385-2.

[30] Rubinstein RY, Kroese DP, "The cross-entropy method. A unified approach to combinatorial optimization, MonteCarlo simulation and machine learning," NY: Information Science and Statistics, Springer, 2004, doi: 10.1007/9781-4757-4321-0.

[31] Karim Sebaa a,b, Mounir Bouhedda., Abdelhalim Tlemçani, Noureddine Henini., "A Location and tuning of TCPSTs and SVCs based on optimal power flow and an improved cross-entropy approach," Electrical Power and Energy Systems, vol. 54, 2014, pp. 536-545, doi: 10.1016/j.ijepes.2013.08.002.

[32] Karim Sebaa, Ayetül Gelen, Hassan Nouri, "Cross-entropy method for distribution power systems reconfiguration," John Wiley \& Sons, Ltd, vol. 1, no. 3, pp. 1-18, 2019, doi: 10.1016/j.ijepes.2013.08.002.

[33] Deb,K., Pratap, A.,Agarwal,S., Meyarivan,T, "A fast elitist non-dominated sorting genetic algorithm," NSGAII, IEEE Transactions on Evolutionary Computation, vol. 6, pp. 182-197, 2002.

[34] Acharjee, P., "Optimal power flow with UPFC using security constrained self adaptive differential evolutionary algorithm for restructured power system," Int. J. Electr. Power Energy Syst, vol. 76, pp. 69-81, 2016, doi: 10.1016/j.ijepes.2015.09.025.

[35] Manoranjitham, G.E. Alagarsamy, S., "Application of firely algorithm on optimal power flow control incorporating simplified impedance UPFC model," Int. J. Electr. Power Energy Syst, vol. 71, pp. 358-363, 2015, doi: 10.1016/j.ijepes.2015.03.009.

[36] Taher, S.A., Amooshahi, M.K., "New approach for optimal UPFC placement using hybrid immune algorithm in electric power systems," Electrical Power and Energy Systems, vol. 43, no. 1, 2012, pp. 899-909, doi: 10.1016/j.ijepes.2012.05.064.

\section{BIOGRAPHIES OF AUTHORS}
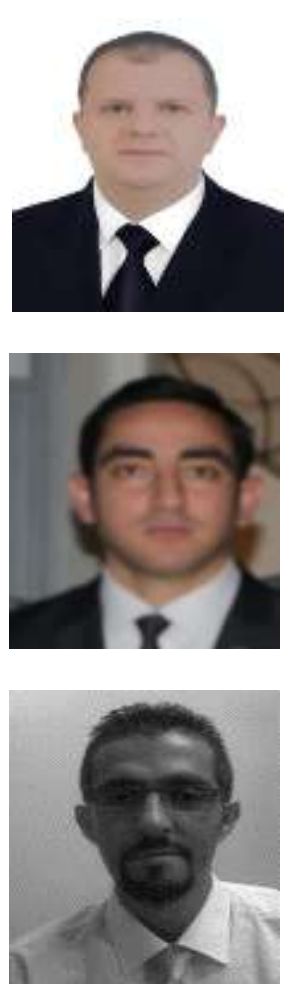

Messaoud Belazzoug received the B.Sc. and M.Sc. degrees from the Polytechnical National School, Algiers in 1997 and 2001, respectively. He received his Ph.D. degree in electricity engineering from USTHB University, Algiers, Algeria in 2011. Currently, he is a Lecturer with the Faculty of Electrical Engineering Technology, University of Blida 1, Saad Dahlab, Blida City, Laboratory of Electrical Systems and Telecommand (LABSET), Electronics Department, Algeria. His main research interests include power system analysis, transmission systems, optimization, power quality and load forecasting.

Chanane Abdallahreceived his Licence and Master degrees in in electrical engineering from blida 1 universityin 2013, Algeria. He is with the department of electrical engineering in Blida 1 university Algeria. Currently, he is a Lecturer with the Faculty of Electrical Engineering Technology, university of Blida 1.His area of interest is the application of meta heuristic algorithms in power system analysis.

Karim Sebaa received his Electrical Engineering degree and Magister in High Voltage and Power Systems from Ecole Nationale Polytechnique, Algiers in 1998 and 2000 respectively. From September 2007 to March 2009, he was a visiting student at Suplélec French. Since 2003, He has joined the university of Medea, Algeria where presently he is full professor of Power Systems. His researches include Power system dynamics, distribution power systems and green energies penetration topower systems. 